Kerem AKÇA /Hard Bilim Kurgu Usulü Humanoid Robot Tanımı

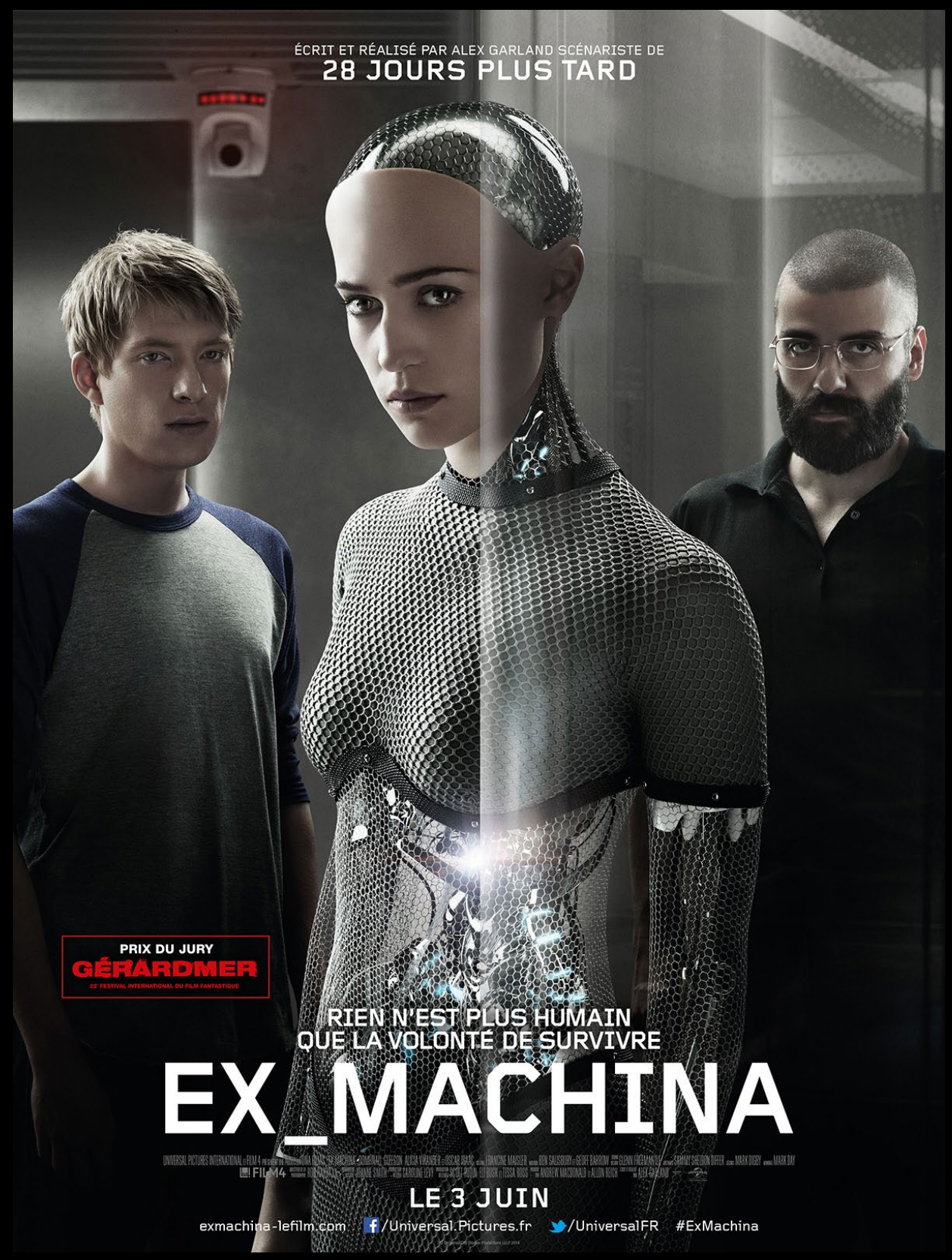




\section{Hard Bilim Kurgu Usulü Humanoid Robot Tanımı}

\section{Kerem AKÇA*}

"Ex Machina”, insan-robot ilişkisine dair, Frankenstein, yapay zekâ ve yeni medya girişimciliği anahtar kelimeleriyle hatırlanacak, farklı okumalara açık bir bilim kurgu filmi. Alex Garland, ilk yönetmenlik denemesinde çıtayı yükseltmese de bir ağırlık hissettiriyor.

Alex Garland'ın hem yazıp hem yönettiği ilk film. Üç Danny Boyle filminin senaristi olarak bildiğimiz yaratıcı esasen bir edebiyat. Bu filmle de farklı bir görev üstlenmeye başlıyor. Açıkçası "Ex Machina” yönetmenlik konusunda duruşu olan ama tökezleyen bir film. Güneş ışığını içeri geçirip mat renkleri açığa çıkarmak bir tercih fakat 103 dakikayı besleyecek bir hikâye yok burada.

\section{Sinema Terimi, Robot, Cyborg ve Ötesi}

Açıkçası "deus ex machina" terimi sinemada kilittir. Belirleyicidir. Olayların beklenmedik bir "Tanrı" eliyle çözülmesini anlatır. Bu bağlamda filmin bu ismi alması güzel, okumaları zenginleştiriyor. Ama mikroorganizmalardan yaratılan "yapay zekâlı robot" tanımı "Aşk"ın (“Her", 2013) sunduğu aşk objesi kadar yenilikçi değil. Dünyanın en çok girilen "arama motoru"nun sahibi ile bilgisayar programcısı arasındaki "test" meselesi tam bir maçoluk imtihanı gibi.

Buna paralel olarak kullanılan aksesuarları düşününce siberpunk teknolojisiyle, internet jenerasyonuyla açıklanamayacak bir "1970 öncesi bilim kurgusu” var. "Hard bilim kurgu" alanına giriş çok bariz bir tercih. "Yaratıcı-yaratılan" ilişkisi, bu türün sevdiğimiz dehlizlerini de akla getiriyor. Açıkçası bu kaynaktan "kadınlar ve cinsellik" konu başlığına girilmesi bir tarafa, deneye sokulan "humanoid (insana benzeyen) robot" tanımı da fazla gördüğümüz bir tür değil. "Cyborg" ile "android" arası bir model denemesi.

* Sinema Yazarı DOI: $10.37679 /$ trta.1002532 


\section{En Ilkel Dürtülere Götürüyor}

Aslında Garland, "Frankenstein" hikâyesindeki konseptten, ilişkiden feyz almış. Onun üzerine "Yapay Zekâ"yı (“A.I.", 2001) ve “Demon Seed"i (1977) yerleştirmiş. Kubrick' in projesinde bir çocuğa yüklenen bu tanım, burada humanoid bir robot yoluyla daha olgun bir deneye sokuluyor. Açıkçası "beden derisi”nin değişiminden iç malzemelerine kadar çok özenli bir robot tanımı var. Ava, Kike Maillo'nun “Eva”sı (2011) kadar külüstür değil.

Alicia Vikander, bu varlığa göz kamaştırıcı bir çekicilik kattyor. Adeta vücudunun her parçasından bir zarafet akıyor. Burada da Isaac ile Gleeson biraz bu yüzden çatı̧ıyor. Film; insanoğlunun en ilkel dürtülerini, cinsel arzularını kontrol edememesinin bir tezahürü gibi.

Araya bir "makine" koyarak da aslında insan-robot kırması üretimlerin insanlığı alt ettiği filmlerden bir kapı aralıyor. Ama tercih ettiği modelle devrimci "Westworld" (1973) gibi değil, tek mekânda geçen ve alay konusu olan "Demon Seed" gibi bir izlenim bırakmaya daha çok yaklaşıyor. Gleeson-Isaac çatışması, işin ucunu Prometheus'a, "Star Trek"e kadar götürüp katmanlar açıyor. Mitolojik okumalar da isteyenler için devreye giriyor.

\section{Yeni Medya Meslekleri}

Ama Garland'a "Sahil"deki ("The Beach", 2000), "Yargıç Dredd"deki ("Dredd", 2012) kafayı bulmaya "öznel" bakan görsellikler yakışıyor. Bunun için ayrı bir rejisör lazım. Buradaki "klasik" aşkı, mesafeli fütürizm, yabancılaştırma arzusu onun ruhunu karşılamıyor. Aynen sadece senaristliğini yaptı̆̆ "Beni Asla Bırakma"da (“Never Let Me Go", 2010) olduğu gibi bir nebze ruhsuz duran bir alt tür örneğiyle yüzleşiyoruz.

"Ex Machina", Frankenstein, yapay zekâ ve robot anahtar kelimeleriyle akla gelecek bir çalışma. Yeni dünya mesleği olan "arama motoru CEO'luğu"nun yarattğı teknolojik çılgınlığın sonuçlarına bakıyor. Aslında bir çeşit sanal Frankenstein, seksi android yaratiyor. Ama yaratılan kavramına Almodovar'ın "iç̧imdeki Deri"si ("La Piel Que Habito", 2011) veya Teshigahara'nın "The Face of Another"। ("Tanin No Kao", 1966) gibi özgün yanaşıyor mu tartşıılır. Deney motifi zaman zaman 30'lara, 50'lere, 60'lara kadar götürebiliyor bizi. Isaac de yeni medya girişimcisi olmasına karşın o dünyadan kopup gelmiş gibi. Bu eylem, filmin iddialı durmasını engelliyor. 


\section{Farklı Okumalara Açık}

"Ex Machina", genel anlamda bir tempo sorunu da çekiyor. Sanatsal olmak isteyince irtifa kaybeden açılar ve akıcı durmayan kurgu, robot-insan ilişkisinin katmanlarını daha iyi takip edebilmek için. En az "Chappie" (2015) kadar yaratıcı bir robot tanımı var. Alicia Vikander'ın sadece vücut parçalarıyla dahi zarif durup büyülediği cesur Ava performansı görülmeye değer. Finali söylemek istemesek de ismiyle "Havva"ya denk gelme kolaycılığı dışında karakter tutuyor. Vikander'ın "yeni Cate Blanchett" olma işlevini karşılıyor.

Hiç sanal gerçekçilik kokmayan robot-insan ilişkisine bakabilmek özenli, tanrı, çocuk, kadın ve yaratan meselelerindeki serbestlik içine alabiliyor. Süre haddini bir kenara bırakınca "Ex Machina" alt metinleriyle farklı bir haz veriyor.

\section{Garland Bilim Kurguda Bir Ekol Oluşturma Çabasında}

Ama uzay gotiği bilim kurgusu “Gün Işığı”nın (2007) sadece senaryosuyla da benzer arayışlar içerisindeki senarist Garland namına hard bilim kurgu üzerinden yürüyüp "Yok Oluş" (“Annihilation”, 2018) ile ulaştığı nokta daha tehditkârdı. Orada "Lena" üzerinden canlanan feminist ve çevreci bir "Stalker" yaratma çabası anlamlı ve kalıcıydı.

2020'de gelen "Devs" dizisi ise bir yazılım mühendisinin dünyasını kuantum hesaplama üzerine kurulu bir "dijital zekâ" ile sarıyor. Oradaki görsel efektler benzer bir yaklaşıma sahip. Bu durum da "Ex Machina"yı Garland külliyatında her şeyin temeli hâline getiriyor. 